\title{
UJI KINERJA ALAT PENYULINGAN NIRA AREN MENJADI BIOETANOL DI KELOMPOK TANI HUTAN TAYAPU DESA TALAWAAN KECAMATAN TALAWAAN KABUPATEN MINAHASA UTARA
}

\author{
Performance Evaluation of Bioethanol Distillation from Palm Sap on Hutan Tayapu \\ Farmer Group in Talawaan Village, Talawaan District of North Minahasa Regency \\ Trivano Solar ${ }^{1}$, Frans Wenur², Lady C. Ch. E. Lengkey ${ }^{2}$ \\ ${ }^{1)}$ Mahasiswa Program Studi Teknik Pertanian \\ ${ }^{2)}$ Dosen Program Studi Teknik Pertanian \\ Jurusan Teknologi Pertanian Fakultas Pertanian, Universitas Sam Ratulangi, Manado \\ Jl. Kampus UNSRAT Manado 95115. \\ *Email: trivanosolar@gmail.com
}

\begin{abstract}
This study aims to determine the performance of the distillation tool aid by the North Sulawesi Forestry Service for the Hutan Tayapu Farmer Group consisting of temperature conditions in the distillation process, alcohol content, distillation rate, product yield, and energy consumption as well as to calculate the energy efficiency of the distillation tool.

This research uses experimental methods. Data is presented in tables and graphs, then computed and analyzed descriptively. Bioethanol production is carried out 2 times each using 100 liters of palm sap. The results showed that the distillation process took place at a temperature ranging from $29.2{ }^{\circ} \mathrm{C}$ to $100.9{ }^{\circ} \mathrm{C}$. The obtained alcohol content ranged from $26 \%$ to $64 \%$, with energy efficiency of $4.96 \%$ for the appliance, and the distillation rate in the range of 1.87-8.40 liter/hour.
\end{abstract}

Key words: palm sap, bioethanol, performance evaluation, energy efficiency

\section{PENDAHULUAN}

Aren (Arenga Pinnata) salah satu jenis tanaman palma yang serbaguna dan hampir tersebar di seluruh wilayah Indonesia. Hampir semua bagian pohon ini bisa digunakan dan dimanfaatkan untuk berbagai kebutuhan mayarakat, baik dari segi fisik berupa akar, ijuk, daun maupun dari segi produksi berupa kolang-kaling, nira, dan pati/tepung. Nira aren dapat diolah menjadi minuman segar, difermentasi menjadi tuak nira, dijadikan sirup aren atau diolah lebih menjadi gula aren, gula semut.

Pengolahan nira aren menjadi etanol sudah umum dilakukan petani aren, antara lain di daerah Minahasa, Sulawesi Utara, 
dengan cara menampung nira hasil sadapan dalam tangki selama 2-3 hari tanpa menggunakan stater atau ragi, nira hasil fermentasi kemudian disuling dengan alat penyulingan sederhana, akan menghasilkan bioetanol berkadar $25-35 \%$ etanol (Lay et al., 2004).

Petani aren yang berada di desa Talawaan, Kecamatan Talawaan, Kabupaten Minahasa Utara, banyak memanfaatkan nira aren menjadi bioetanol tradisional (captikus) dibandingkan dengan membuat gula aren karena lebih mudah dalam proses pembuatan dan memiliki nilai ekonomi yang lebih tinggi. Dalam pembuatan bioetanol tradisional (captikus) petani yang berada di desa Talawaan, Kecamatan Talawaan, Kabupaten Minahasa Utara, masih menggunakan alat penyulingan dengan cara tradisional. Permasalahan yang dihadapi oleh pengolah etanol (bahasa lokal captikus) pada tingkat petani, adalah kadar etanol tidak seragam dan tidak diketahui dengan pasti (Karouw dan Lay, 2006).

Untuk membantu para petani yang berada di Desa Talawaan, pemerintah melalui Dinas Kehutanan Sulawesi Utara telah memberikan bantuan alat distilasi atau penyulingan kepada kelompok tani Hutan Tayapu yang berada di Desa Talawaan, Kecamatan Talawaan, Kabupaten Minahasa utara. Bantuan alat pertanian ini diharapkan dapat membantu dan mempermudah petani dalam proses produksi dan dapat meningkatkan daya kerja manusia yang ada. Dengan belum adanya informasi data mengenai kinerja alat penyulingan yang berada di kelompok tani Hutan Tayapu tersebut maka penelitian ini akan melakukan uji kinerja alat untuk menghitung dan menentukan berapa besar rendemen yang dihasilkan, laju penyulingan, konsumsi energi yang dipakai dan efisiensi alat.

\section{METODE PENELITIAN}

\section{Alat dan Bahan}

Alat yang digunakan adalah wadah penampung air, gelas ukur, termometer infrared, refraktometer, alkoholmeter, termokopel, drum air, pompa air, tangki air 1100 1. Sedangkan bahan yang digunakan adalah Nira aren sebanyak 200 liter

\section{Metode}

Penelitian dilakukan dengan menggunakan metode eksperimen. Data disajikan dalam bentuk tabel dan grafik, selanjutnya data dihitung dan dianalisa dengan metode deskriptif. Pembuatan bioetanol dilakukan sebanyak 2 kali ulangan masing-masing ulangan sebanyak 100 liter nira aren. Pengukurun suhu dilakukan di berbagai titik yaitu suhu pipa penghubung, suhu uap nira, suhu nira, dan suhu api. Pengukuran suhu api menggunakan termometer infrared dan pengukuran suhu pipa penghubung, suhu uap nira dan suhu nira menggunakan termokopel

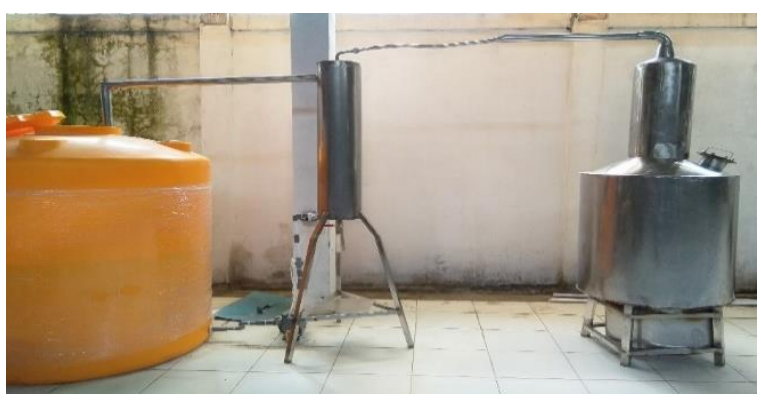

Gambar 1. Alat penyulingan

\section{Prosedur penelitian}

Penelitian diawali dengan menyiapkan nira aren yang dipanen dari pohon aren yang berada di desa Talawaan, kecamatan Talawaan, kabupaten Minahasa Utara sebanyak 100 liter. Sebelum proses fermentasi nira aren akan dihitung kadar gula. Nira aren yang digunakan dalam penelitian alat ini diambil atau dikumpulkan 
dari beberapa petani pada hari yang sama. Nira hasil sadapan selanjutnya dikumpul dan ditampung dalam drum penampungan, untuk sisa dan endapan sebelumnya sengaja tidak dibersihkan, hal ini dimaksudkan agar proses fermentasi dapat terlaksana secara alami dengan bantuan mikroba yang ada pada wadah penampung. Proses fermentasi dibiarkan berlangsung selama 3 hari, dalam proses fermentasi nira aren akan dihitung kadar gulanya. Tujuan dari fermentasi ini dilakukan agar kandungan gula yang ada di nira aren tersebut dikonversikan menjadi etanol

Sebelum melakukan proses penyulingan nira aren yang sudah difermentasi diukur kadar gulanya, setelah itu dimasukan ke dalam tabung penyulingan. Selanjutanya dipanaskan menggunakan kompor. Pada proses penyulingan dilakukan sebanyak dua kali ulangan masing-masing 100 liter.

Uji kinerja alat untuk mengetahui tingkat efisiensi alat berdasarkan tujuan penelitian. Variabel yang diamati dalam pengujian alat ini kondisi suhu pada proses penyulingan, kadar alkohol, laju penyulingan, rendemen hasil, dan konsumsi energi

\section{Parameter penelitian Suhu}

Pengamatan suhu dilakukan setiap 5 menit sekali selama 1 jam pertama setelah itu pengamatan dilakukan setiap 10 menit sekali hingga proses penyulingan selesai. Pengukurun suhu dilakukan di berbagai titik yaitu suhu pipa penghubung, suhu uap nira, suhu nira, dan suhu api. Pengukuran suhu api menggunakan termometer infrared dan pengukuran suhu pipa penghubung, suhu uap nira dan suhu nira menggunakan termokopel.

\section{$\underline{\text { Laju Penyulingan }}$}

Untuk mengukur laju penyulingan digunakan persamaan sebagai berikut (Wenur dan Waromi, 2017):

Laju penyulingan $(l / j a m)$

$$
=\frac{\text { volume hasil bioetanol }(l)}{\text { selang waktu penyulingan }(j a m)}
$$

\section{Rendemen}

Untuk mengukur Rendemen hasil total dan rendemen teruapkan, dengan persamaan (Wenur dan Waromi, 2017):

a. Rendemen Hasil Total (\%)

$$
=\frac{\text { hasil bioetanol }(l)}{\text { bahan nira awal }(l)} \times 100 \%
$$

b. Rendemen Teruapkan (\%)

$$
=\frac{\text { hasil bioetanol }(l)}{\text { jumlah nira teruapkan }(l)} \times 100 \%
$$

dimana : jumlah nira teruapkan $(1)=$ jumlah nira awal (1) - jumlah nira akhir (1).

\section{Perhitungan Konsumsi Energi}

a. Perhitungan Konsumsi Energi Penggunaan Gas Liquified Petroleum Gas (LPG)

Sumber panas pada alat penyulingan ini berupa gas LPG. Nilai kalor gas LPG adalah $47080.56 \mathrm{~kJ} / \mathrm{kg}$ (Yudisworo, 2010).

$\mathrm{E}$ gas LPG $=\left(E_{\text {gas }} L P G\right) \times\left(m_{\text {gas }} L P G\right)$

Keterangan :E gas LPG = konsumsi energi

dalam penggunaan gas LPG $(\mathrm{kJ})$

$E_{\text {gas }} L P G=$ nilai kalor gas $L P G$ per

kilogram $(\mathrm{kJ} / \mathrm{kg})$

$m_{\text {gas }} L P G=$ massa gas LPG yang digunakan $(\mathrm{kg})$

b. Perhitungan Konsumsi Energi Listrik Pompa Air

Penelitian ini menggunakan pompa air yang berenergi listrik. Energi listrik menghidupkan pompa untuk mendistribusikan air menuju kondensor. Perhitungan konsumsi energi listrik pompa : 
$E=\mathrm{V} \times \mathrm{I} \times t$

Keterangan : $\mathrm{E}=$ energi listrik pompa air (J)

$$
\begin{aligned}
& \mathrm{V}=\text { tegangan listrik (Volt) } \\
& \mathrm{I}=\text { kuat arus (Ampere) } \\
& \mathrm{t}=\begin{array}{l}
\text { waktu proses distilasi } \\
(\text { sekon) }
\end{array}
\end{aligned}
$$

\section{Efisiensi Penggunaan Energi alat}

Efisiensi Penggunaan Energi alat dihitung dengan persamaan sebagai berikut

Efisiensi Energi Alat $=$

$\frac{\text { Energi untuk menghasilkan Bioetanol }}{\text { Total Input Energi }} \times 100 \%$

dimana:

Energi Untuk menghasilkan bioetanol = jumlah hasil bioetanol $\times$ panas laten penguapan

Energi total $=$ energi bahan bakar (jumlah Bahan bakar $\times$ nilai kalor) + energi listrik

\section{HASIL DAN PEMBAHASAN}

\section{Suhu}

Hasil pengamatan sebaran suhu pada beberapa titik pengamatan selama percobaan 2 disajikan pada Gambar 2. Pada saat pengujian pertama lamanya waktu proses penyulingan 300 menit. Bioetanol mulai menetes pertama kali dimenit ke 54 . Sedangkan pada pengujian kedua lamanya waktu proses penyulingan 430 menit. pada proses penyulingan ini bioetanol menetes dimenit ke 47 lebih cepat 7 menit dari pengujian pertama. Setelah bioetanol telah menetes nyala api kompor dikecilkan karna suhu nira sudah mendekati suhu titik didih air dan pompa air dinyalakan

Pada pengujian kedua ini waktu distilasi berlangsung lebih lama dibandingkan pengujian pertama. Hal ini disebabkan karena pada saat waktu menurunkan suhu api kompor, nyala apinya lebih kecil dari waktu pengujian pertama.
Seperti terlihat pada Gambar 2, menurut Wenur dan Waromi (2017) Seiring dengan meningkatnya suhu nira yang terus mendekati suhu didih air, maka suhu uap di puncak pipa maupun suhu uap di pipa kondensasi juga terus meningkat mendekati suhu didih nira. Suhu yang terus meningkat di pipa kondensasi ini akan menghambat proses kondensasi etanol selanjutnya, selain itu suhu nira yang tinggi memungkinkan makin banyak komponen air yang turut teruapkan yang berakibat pada menurunnya kadar etanol dari hasil.

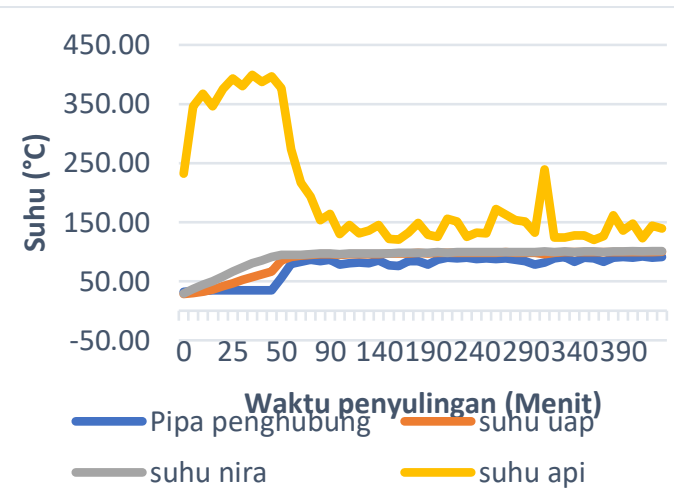

Gambar 2. Sebaran Suhu (Pengolahan 2)

\section{Volume Bioetanol, Kadar Alkohol dan Laju Penyulingan}

Kadar alkohol dan laju penyulingan di tampilkan dalam Gambar 3. Dalam setiap pengujian distilat yang dihasilkan memiliki volume dan kadar etanol yang berbeda. Hal ini dipengaruhi oleh pengontrolan suhu selama proses penyulingan.

Kadar alkohol pada awal setelah tetes pertama dihasilkan adalah paling tinggi. Seperti terlihat pada Gambar 3, Pada pengujian pertama pada saat waktu 15 menit pertama kadar alkohol yang diperoleh sebesar 58\% dan terus menurun pada 15 menit berikutnya sampai di 15 menit terakhir kadar alkoholnya sebesar 26\% dan setelah dicampurkan semuanya distilat yang 
dihasilkan memiliki kadar alkohol sebesar 46\%. Sedangkan Pada pengujian kedua pada 15 menit pertama kadar alkohol yang diperoleh sebesar $64 \%$ dan terus menurun pada 15 menit berikutnya sampai di 15 menit terakhir kadar alkoholnya sebesar $28 \%$ dan setelah dicampurkan semuanya distilat yang dihasilkan memiliki kadar alkohol sebesar 50\%. Pada pengujian kedua ini waktu penyulingan berlangsung lebih lama dan laju penyulingannya rendah dibandingkan pengujian pertama. Hal ini diduga dari penggunaan suhu penyulingan di pengujian pertama lebih tinggi. Hal ini menjelaskan bahwa pengontrolan suhu selama penyulingan penting dan harus diupayakan tetap pada kisaran suhu didih etanol sehingga komponen air dalam nira tidak turut teruapkan. Untuk dijadikan alkohol teknis kadar alkohol pada pengujian ini masih rendah perlu ditinggatkan dengan redistilasi kembali.

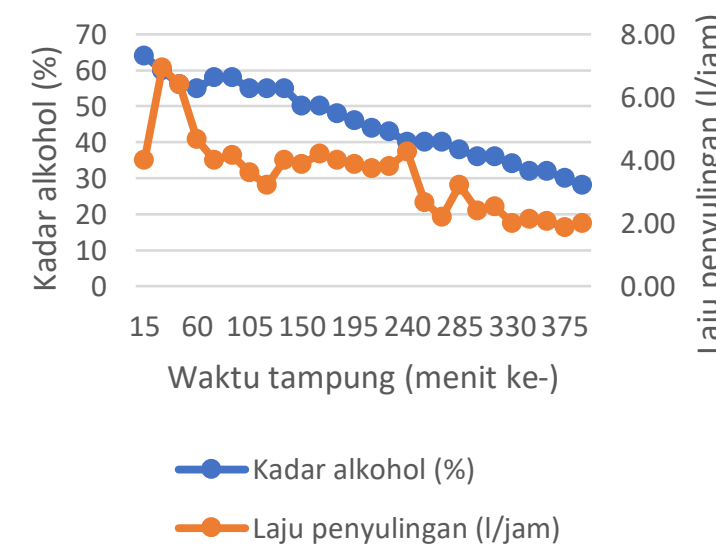

Gambar 3. Kadar Alkohol dan Laju Penyulingan (Pengolahan 2)

Pada pengujian pertama laju penyulingan tertinggi ada di menit 45 yaitu $8,401 /$ jam dengan volume bioetanol yang dihasilkan sebesar $1260 \mathrm{ml}$ dengan kadar alkohol sebesar 55\%. Sedangkan Pada pengujian kedua laju penyulingan tertinggi ada di menit 30 yaitu 6,93 1/jam dengan volume bioetanol yang dihasilkan sebesar $1040 \mathrm{ml}$ dengan kadar alkohol sebesar $60 \%$.

\section{Rendemen}

Menurut Wenur dan Waromi (2017) rendemen menunjukkan persentase perolehan hasil dari suatu proses penyulingan. Rendemen dapat diamati sebagai persentase perolehan hasil terhadap total masukan bahan atau terhadap jumlah nira yang teruapkan. Dari hasil pengamatan diketahui rendemen total sebesar 13,41\% dan rendemen yang teruapkan diperoleh sebesar $58.30 \%$. Pengujian kedua rendemen total pengolahan bioetanol $13,77 \%$ dan rendemen teruapkan $72.45 \%$ lebih tinggi dari pengujian pertama. Hal ini diduga karena pada saat proses pengujian pertama terjadi kebocoran di pipa penghubung di tengah-tengah proses penyulingan berlangsung. Sehingga uap yang dialirkan ke tabung kondensor sudah ada yang keluar lewat pipa yang bocor itu. Rusli (1997) menyebutkan bahwa semakin lama suatu bahan menerima panas, maka proses difusi akan semakin meningkat sehingga proses distilasi menjadi optimal. Semakin tinggi suhu proses distilasi semakin cepat proses tersebut berlangsung sehingga distilat yang diperoleh semakin banyak Guenther (1987).

\section{Konsumsi Energi}

Pada proses penyulingan memakai atau mengkonsumsi energi, yaitu energi penggunaan gas LPG dan energi listrik penggunaan pompa air.

\section{Konsumsi Energi Penggunaan Gas (LPG)}

Penggunaan gas LPG ini sebagai sumber api atau sumber panas dalam proses penyulingan. Penggunaan gas LPG membantu mempercepat

Penggunaan gas LPG membantu mempercepat pemanasan nira aren dalam proses penyulingan. Konsumsi energi gas 
yang dipakai dalam pengujian pertama sebesar 3,8 kg atau $178906,1 \mathrm{~kJ}$ lebih rendah dibanding dipengujian kedua yang mencapai 4,445 kg atau 209273,1 kJ. Hal ini disebakan dipengujian kedua waktu penyulingannya lebih lama sehingga konsumsi energi penggunaan gas LPG yang dipakai lebih besar.

\section{Perhitungan Konsumsi Energi Listrik Pompa Air}

Air yang digunakan berfungsi sebagai media pendingin dalam proses kondensasi. Untuk menjaga sirkulasi air agar tetap dingin, air dipompa menggunakan pompa air yang digerakkan menggunakan energi listrik. Pompa air dinyalakan saat bioetanol sudah mulai menetes.

Pada pengujian pertama pompa air dinyalakan selama 240 menit dan pada pengujian kedua pompa air dinyalakan selama 390 menit. Konsumsi energi listrik yang dipakai dalam pengujian pertama sebesar 4,9104 kJ lebih rendah dibanding dipengujian kedua yang mencapai 7,9794 kJ. Hal ini disebakan oleh lamanya proses penyuligan pada pengujian kedua.

\section{Efisiensi Penggunaan Energi Alat}

Efisiensi energi alat adalah perbandingan antara energi yang digunakan untuk menghasilkan bioetanol terhadap total energi yang digunakan selama proses pengolahan meliputi energi bahan bakar LPG dan energi listrik. Efisiensi energi alat pada pengujian pertama sebesar $4,96 \%$ dan efisiensi energi alat pengujian kedua sebesar $4,35 \%$

\section{KESIMPULAN}

\section{Kesimpulan}

1. Pengujian pertama menghasilkan etanol dengan kadar $46 \%$ dan volume sebesar $13.410 \mathrm{ml}$. Pengujian kedua menghasilkan etanol dengan kadar 50\% dan volume sebesar $13.765 \mathrm{ml}$.

2. Rendemen total pada pengujian pertama sebesar $13,41 \%$ dan rendemen yang teruapkan diperoleh sebesar 58,30\% dan pada pengujian kedua sebesar $13,77 \%$ dan rendemen teruapkan diperoleh sebesar $72,45, \%$.

3. Laju penyulingan berkisar pada 4.078.40 1/jam dan pada pengujian kedua berkisar pada 1,87- 6.93 1/jam. Laju penyulingan tergantung pada suhu penyulingan yang digunakan.

4. Konsumsi energi penggunaan gas LPG pada pengujian pertama adalah 178906,1 kJ dan pada pengujian kedu sebesar 209273,1 kJ. Konsumsi penggunaan energi pompa listrik pada pengujian pertama adalah 4,9104 kJ dan pada pengujian kedua $7,9794 \mathrm{~kJ}$.

5. Efisiensi energi alat pada pengujian pertama sebesar $4,96 \%$ dan pada pengujian kedua sebesar $4,35 \%$.

\section{DAFTAR PUSTAKA}

Guenther, E. 1987. The Essential Oils. Penerjemah S. Ketaren. Minyak Atsiri (Jilid I). UI-Press, Jakarta.

Karouw S dan A. Lay. 2006. Nira aren dan teknik pengendalian produk olahan. Buletin Palma; (31):116- 125.

Lay A, R. T. P. Hutapea, J. Tuyuwale, J. O. Sondakh, dan A.L Polakitan. 2004. Pengembangan komoditas aren di Daerah Minahasa Sulawesi Utara. Prosiding Seminar Nasional Pengembangan Tanaman Aren. Tondano, Juni 2004.

Rusli, S. 1997. Konstruksi Unit Penyulingan Sereh Wangi, Sereh Dapur Dan Cengkeh. Lembaga Penelitian Tanaman Industri 
Uji Kinerja Alat Penyulingan Nira Aren .........Trivano Solar, dkk.

Wenur, F. dan Y. Waromi 2017. Studi Pengolahan Bioetanol Tradisional Dari Nira Aren Di Minahasa Selatan. Jurnal Teknologi Pertanian Vol.8 (2): $1-7$

Yudisworo. 2010. Studi Alternatif Penggunaan BBG Gas Elpiji untuk Bahan Bakar Mesin Bensin Konvensional. Teknik Mesin : Universitas 17 Agustus 1945 Cirebon. 